\title{
NONALCOHOLIC FATTY LIVER DISEASE IN MENOPAUSAL WOMEN
}

\author{
Gesira Soares de Assis FLORENTIN01, 2, Helma Pinchemel COTRIM'1 ${ }^{1}$, Consuelo Padilha VILAR ${ }^{1,2}$, \\ André Vinícius de Assis FLORENTINO3 ${ }^{3}$, Geruza Maria Almeida GUIMARÃES ${ }^{2}$ and \\ Victorino Spinelli Toscano BARRET0 ${ }^{4}$
}

\begin{abstract}
Context - Nonalcoholic Fatty Liver Disease (NAFLD) is common in postmenopausal women. It is associated with metabolic syndrome. However, the influence of hormone replacement therapy in NAFLD development in these women needs to be investigated. This study aimed to describe the clinical characteristics of NAFLD in postmenopausal women, and the relationship between hormone replacement therapy and this disease. Methods - From April 2009 to April 2011, 292 postmenopausal women from National Health System from Northeast of Brazil were selected, and 251 were included in this study. Menopause was defined as the absence of menstruation for 12 consecutive months in otherwise healthy women. Criteria to NAFLD included: presence of steatosis on abdominal ultrasound; history of alcohol consumption less than $20 \mathrm{~g} /$ day and exclusion of other liver diseases. All women underwent a clinical evaluation. Standard univariate and multivariate analyses were performed to evaluate the results. Results - The mean age was $56.5 \pm 6.7$ years. Hormone replacement therapy was referred by $21.1 \%$ (53) women and $78.9 \%$ (198) was not. Prevalence of NAFLD was $37.1 \%(93 / 251)$ in postmenopausal women, 26,4\% (14/53) in the group with hormone replacement therapy and $39,9 \%$ (79/198) without hormone replacement therapy. Gamma-glutamyl transpeptidase $(P=0.001)$, alanine transaminase $(P<0.01)$, ferritin $(P<0.001)$ and insulin resistance (homeostatic model assessment of insulin resistance $\geq 3)(P<0.001)$ were higher in the group of women with NAFLD diagnosis who did not referred the use of hormone replacement therapy. Metabolic syndrome was also more frequent in women with NAFLD, who did not refer hormone replacement therapy. Conclusion - In conclusion this data suggests elevated prevalence of NAFLD in postmenopausal women; negative association of hormone replacement therapy and NAFLD. HEADINGS - Fatty Liver. Hormone replacement therapy.
\end{abstract}

\section{INTRODUCTION}

Nonalcoholic fatty liver disease (NAFLD) is characterized by the focal or diffuse accumulation of fat in the liver parenchyma of patients who deny abusive alcohol consumption ${ }^{(12)}$. It prevalence ranges from $3 \%$ to $24 \%$ in the general population ${ }^{(3)}$, and reaches $89.5 \%$ among severe obese patients ${ }^{(7)}$. It increases with increasing age ${ }^{(27)}$, and is more prevalent among men and non-Hispanic whites ${ }^{(3)}$, and in individuals with hepatitis $\mathrm{C}$ virus ${ }^{(5)}$.

NAFLD is frequent in postmenopausal women (PMW) and it is usually associated with metabolic syndrome. The influence of hormone replacement therapy (HRT) in NAFLD development in these women has been discussed ${ }^{(3)}$. In menopause occurs a decrease in the liver ability to oxidize fatty acids, and an increased on lipogenesis that causes excessive accumulation of hepatic fat and culminates with inflammation ${ }^{(21)}$.

The estrogen deficiency causes body fat redistribution, with accumulation of visceral fat, which can influence the development and progression of NAFLD $^{(13)}$.
An experimental study with ovariectomized rats showed that the absence of estrogens could stimulate fat accumulation in the liver, and that ovariectomized rats subjected to an endurance program had decreased fat in the liver and abdomen ${ }^{(6)}$. It was also observed lower levels of ALT in type 2 diabetics undergoing HRT for 6 months ${ }^{(16)}$.

The present study describes the clinical characteristics of NAFLD in PMW, and investigates the relationship between HRT and this liver disease.

\section{METHODS}

\section{Study design and population selection}

In a sectional study, a total of 292 PMW coming from the National Health System from Northeast of Brazil, who reported the use of $\operatorname{HRT}(\mathrm{G} 1)$ or who denied the use $(\mathrm{G} 2)$, were analyzed. The use of HRT was defined as the use of estrogen in hysterectomized PMW or estrogen associated with progesterone when the uterus was present, or also the use of tibolone, by oral or transdermal routes for more than 6 months.

\footnotetext{
Programa de Medicina e Saúde, Faculdade de Medicina da Bahia, Universidade Federal da Bahia; 2 Universidade Federal de Campina Grande, Hospital Universitário Alcides Carneiro, Campina Grande, Paraiba; ${ }^{3}$ Faculdade de Ciências Médicas de Campina Grande, Paraiba; ${ }^{4}$ Instituto do Fígado de Pernambuco.

Correspondence: Prof. Helma Pinchemel Cotrim. Programa de Pós-graduação em Medicina e Saúde - Complexo Hospitalar Universitário Professor Edgard Santos Universidade Federal da Bahia, Rua Augusto Viana, S/N, $5^{\circ}$ andar - 40110-060 - Salvador, BH, Brasil. E-mail: helmacotrim@terra.com.br
} 
The sample was calculated by the method of proportions according to Arkin and Colton ${ }^{(1)}$.

The indication for HRT use was made by the gynecologists who accompanied the PMW based on the clinical features and climacteric symptoms. The duration of menopause ranged from 1 to 5 years (101 women/40.2\%), 6-10 years (70 women $/ 27.9 \%$ ) and above 10 years ( 80 women $/ 31.9 \%$ ). The use of HRT was confirmed by patients report during the interview.

From April 2009 to April 2011, 251 women were included and evaluated. This study was conducted in accordance with the Declaration of Helsinki an the Institutional Ethics Committee from the Federal University of Campina Grande approved the study under the number 20080212-040. Written informed consent was obtained before include the participants.

\section{Clinical evaluation}

All participants had a complete physical exam and answered a questionnaire that included demographic characteristics (age, marital status and family income) and physical activity level (example: participation in any kind of sport at least three times a week), history of obesity, dyslipidemia and diabetes; history of alcohol intake and other illicit drugs usage.

Laboratory evaluation included: viral hepatitis infection markers for B virus (HBsAg) and $\mathrm{C}$ virus (anti $\mathrm{HCV}$ ), ALT, AST, GGT, ferritin, total cholesterol, high-density lipoprotein cholesterol, low-density lipoprotein cholesterol, triglycerides, glucose, insulin, transferrin saturation. Levels of follicle-stimulating hormone higher than $50 \mathrm{mIU} / \mathrm{mL}$ were determined to confirm menopause in hysterectomized women without oophorectomy. PMW with antinuclear factor reagent 1/80 were tested for anti-liver-kidney microsomal antibody and anti-smooth muscle antibodies to rule out autoimmune hepatitis.

Menopause was defined in woman who has been amenorrhea (absence of any menstruation) for 12 or more months.

The metabolic syndrome (MS) was defined according to the National Cholesterol Education Program's Adult Treatment Panel III report ${ }^{(14)}$. Abdominal ultrasound exam was performed in all patients by a single radiologist in the same institution, and steatosis was classified in grades I, II and III, with the grade I corresponding to the increase of the echogenicity of the liver parenchyma, II (hepatic hyperechogenicity associated with attenuation of the sound beam in posteriors planes) and III (the sum of the above plus the loss of definition in liver vascular structures and the diaphragm).

Insulin resistance was calculated using the Homeostatic Model Assessment for Insulin Resistance, and a value $\geq 3$ was considered abnormal ${ }^{(15)}$.

The hepatic enzymes were considered elevated when their values were at least 1.5 times their normal maximal values and the ferritin when its greater than its normal maximal value $(200 \mathrm{ng} / \mathrm{mL})$.

Other liver diseases were excluded: $\mathrm{B}$ and $\mathrm{C}$ virus (HBsAg or anti HCV positive); autoimmune, metabolic; hepatotoxic drugs use; hysterectomy with functioning ovaries (defined as a follicle-stimulating hormone value less than $50 \mathrm{mIU} / \mathrm{mL}$ ), diabetes and hypotiroidism.

\section{NAFLD criteria}

History of ethanol intake $\leqslant 20 \mathrm{~g} /$ day; hepatic steatosis on abdominal ultrasound; exclusion of drug use and other liver diseases ( $\mathrm{B}$ and $\mathrm{C}$ hepatitis virus, hemochromatosis and autoimmune hepatitis).

\section{Statistical Analysis}

Data were processed and analyses were performed using Statistical Package for the Social Sciences software (SPSS Inc., Chicago, IL, USA, Release 17.0.1, 2008). Continuous variables were summarized with means and standard deviations while categorical variables were presented in frequencies and percentages. Comparisons between the means of two groups were performed using Student's $t$-test for independent samples. Chi-square and Fisher's exact tests were used to test associations between categorical variables. One-way analysis of variance was used to compare the means of the four groups. This was followed by the Bonferroni's post hoc test. Logistic regression analysis was used for the study of prognostic factors and to obtain the adjusted odds ratios and their exact $95 \%$ confidence interval. All comparisons performed were two-tailed, $P$ values were calculated and significance level was set to equal or less than 0.05 .

\section{RESULTS}

The mean age of the 251 participants was $56.5 \pm 6.7$ years. Further demographic data are shown in Table 1. Fifty-three $(21.1 \%)$ women referred to use HRT (G1) and $198(78.9 \%)$ did not (G2). The prevalence of NAFLD was $37.1 \%$ in all sample, and was lower in G1 - 26,4\% (14/53) than in G2 $39,9 \%(79 / 198)$.

The time of menopause varied as follows: 101 women $(40.2 \%)$ were in menopause between 1 and 5 years; 70 women $(27.9 \%)$ between 6 and 10 years and 80 women $(31.9 \%)$, above 10 years.

Regarding the HRT usage time, 22 women $(41.5 \%)$ used HRT between 6 months and 2 years, 14 women $(26.4 \%)$ between 2 and 4 years and 17 women (32.1\%) over 4 years.

TABLE 1. Absolute and relative frequencies of demographic data from 251 patients

\begin{tabular}{llcc}
\hline Variables & Category & $\mathrm{N}$ & $\%$ \\
\hline \multirow{2}{*}{ Race } & White & 90 & 35.9 \\
& Black & 18 & 7.2 \\
& Non-white & 143 & 57.0 \\
\hline \multirow{2}{*}{ Educational level } & Illiterate & 20 & 8.0 \\
& HS or less & 190 & 75.7 \\
& PSE & 41 & 16.3 \\
\hline \multirow{2}{*}{ Marital relationship } & With partner & 121 & 48.2 \\
& Without partner & 130 & 51.8 \\
\hline \multirow{2}{*}{ Origin } & Countryside & 9 & 3.6 \\
& Urban area & 242 & 96.4 \\
\hline \multirow{2}{*}{ Income } & 1 - 5 Minimum wages & 234 & 93.2 \\
& $>5$ Minimum wages & 17 & 6.8 \\
\hline
\end{tabular}

HS: High School; PSE: Post-secondary education 
PMW from G2, with and without NAFLD diagnosis, had higher rates of overweight, obesity and insulin resistance when compared with G1. The frequency of MS in the entire group of PMW was 39.8\% (100/251), being higher in patients with NAFLD without using HRT as shown in Table 2.

ALT, GGT and ferritin levels were higher in G2 with NAFLD (Table 3). ALT and ferritin levels were higher in the PMW with grades II and III steatosis in G2 than in women with equal degrees of steatosis in G1 (Table 4). The use of HRT, type of hormone used, route of administration and the duration of HRT use, did not reveal an association with NAFLD according to our results (Table 5).
The multivariate logistic regression model showed that prognostic factors for NAFLD were: presence of MS - Odds Ratio: 2.02 (CI-1.11-3.69), $P=0.02$, homeostatic model assessment of insulin resistance $\geq 3$ - Odds Ratio: 3.73(CI1.63-8.53), $P=0.002$ and obesity - Odds Ratio: 1.91 (CI1.01-3.61) $P=0.046$ ) (Table 6). Additionally, the multivariate analyses also showed that the patients from the G1 were younger than $\mathrm{G} 2(P=0.021)$. Moreover the group $\mathrm{G} 1$ was composed of a higher number of women who were married $(P=0.003)$. The $\mathrm{G} 2$ had lower family income $(P<0.001)$ and a lower level of education $(P=0.700)$, regardless of NAFLD diagnosis.

TABLE 2. Analyzed variables according to the use of hormone replacement therapy associated to NAFLD status

\begin{tabular}{|c|c|c|c|c|c|}
\hline \multirow{2}{*}{ Variables } & \multicolumn{2}{|c|}{ G1 $($ on HRT) $n=53$} & \multicolumn{2}{|c|}{ G2 (without HRT) $n=198$} & \multirow{2}{*}{$P$-value } \\
\hline & NAFLD $n=14$ & No $n=39$ & NAFLD $\mathrm{n}=79$ & No $n=119$ & \\
\hline HOMA IR >3(\%) & $0(0 \%)^{*}$ & $1(2 \%)^{*}$ & $24(30 \%)$ & $9(8 \%)^{*}$ & $<0.001$ \\
\hline Physical activity, $\mathrm{n}(\%)$ & $6(43 \%)$ & $20(51 \%)$ & $29(37 \%)$ & $50(42 \%)$ & 0.514 \\
\hline \multicolumn{6}{|c|}{ Body mass index classification, $\mathrm{n}(\%)$} \\
\hline Normal & $5(36 \%)$ & $4(62 \%)$ & $6(8 \%)$ & $30(25 \%)$ & \\
\hline Overweight & $5(36 \%)$ & $2(30 \%)$ & $38(48 \%)$ & $60(50 \%)$ & $<0.001$ \\
\hline Obese & $4(28 \%)$ & $3(8 \%)$ & $35(44 \%)$ & $29(25 \%)$ & \\
\hline \multicolumn{6}{|c|}{ Metabolic Syndrome, n (\%) } \\
\hline & $5(36 \%)$ & $5(13 \%)$ & $48(61 \%)$ & $42(35 \%)$ & $0.001^{\S}$ \\
\hline
\end{tabular}

HRT: Hormone replacement therapy; NAFLD: Non-alcoholic fatty liver disease; HOMA IR: homeostatic model assessment of insulin resistance; " $(P<0.05)$ significant difference in the group with NAFLD diagnosis without HRT; ${ }^{\S}$ Descriptive level of probability of the chi-square test

TABLE 3. Frequencies of abnormal blood laboratory levels, according to the use of hormone replacement therapy associated to NAFLD diagnosis

\begin{tabular}{|c|c|c|c|c|c|}
\hline \multirow{2}{*}{ Biomarkers Status } & \multicolumn{2}{|c|}{ G1 (on HRT) $n=53$} & \multicolumn{2}{|c|}{ G2 (without HRT) n = 198} & \multirow{2}{*}{$P$-value } \\
\hline & NAFLD $\mathrm{n}=14$ & No $n=39$ & NAFLD $n=79$ & No $n=119$ & \\
\hline Elevated ALT, n(\%) & $2(14 \%)^{*}$ & $2(5 \%)^{*}$ & $16(20 \%)$ & $6(5 \%)^{*}$ & 0.004 \\
\hline Elevated AST, n(\%) & $0(0 \%)$ & $4(10 \%)$ & $6(8 \%)$ & $4(3 \%)$ & 0.249 \\
\hline Elevated GGT, n(\%) & $1(7 \%)^{*}$ & $6(15 \%)^{*}$ & $30(38 \%)$ & $28(24 \%)^{*}$ & 0.011 \\
\hline Elevated Ferritin, $\mathrm{n}(\%)$ & $1(7 \%)^{*}$ & $4(10 \%)^{*}$ & $36(46 \%)$ & $30(25 \%)^{*}$ & $<0.001$ \\
\hline
\end{tabular}

HRT: hormone replacement therapy; NAFLD: Non-alcoholic fatty liver disease; ${ }^{*}(P<0.05)$ significant difference in the group with NAFLD diagnosis without HRT

TABLE 4. Frequencies of abnormal blood laboratory tests, according to the degree of steatosis among the groups

\begin{tabular}{|c|c|c|c|c|c|}
\hline \multirow[b]{2}{*}{ Blood Levels } & \multicolumn{4}{|c|}{ Degree of Steatosis in G1 (on HRT) } & \multirow[b]{2}{*}{$P$-value } \\
\hline & $\begin{array}{c}\text { No Steatosis } \\
\mathbf{n}=39\end{array}$ & $\begin{array}{c}\text { Grade I } \\
\mathrm{n}=9\end{array}$ & $\begin{array}{c}\text { Grade II } \\
\mathrm{n}=3\end{array}$ & $\begin{array}{c}\text { Grade III } \\
\mathrm{n}=2\end{array}$ & \\
\hline Elevated GGT, n (\%) & $6(15.4 \%)$ & $0(0.0 \%)$ & $0(0.0 \%)$ & $1(50 \%)$ & 0.241 \\
\hline Elevated AST, n (\%) & $4(10.3 \%)$ & $0(0.0 \%)$ & $0(0.0 \%)$ & $0(0.0 \%)$ & 1.000 \\
\hline Elevated Ferritin, $\mathrm{n}(\%)$ & $4(10.3)$ & $1(11.1 \%)$ & $0(0.0 \%)$ & $0(0.0 \%)$ & 1.000 \\
\hline Elevated GGT, n (\%) & $28(23.5 \%)$ & $15(38.5 \%)$ & $11(32.6 \%)$ & $4(66.7 \%)$ & 0.053 \\
\hline Elevated ALT, n (\%) & $6(5.0 \%)$ & $6(15.4 \%)$ & $8(23.5 \%)^{*} \S$ & $2(33.3 \%)^{* 8}$ & $<0.001$ \\
\hline Elevated AST, n (\%) & $4(3.4 \%)$ & $2(5.1 \%)$ & $4(11.8 \%)$ & $0(0.0 \%)$ & 0.237 \\
\hline Elevated Ferritin, n (\%) & $30(25.2 \%)$ & $14(35.9 \%)$ & $19(55.9 \%)^{* \S}$ & $3(50.0 \%)^{* 8}$ & $<0.001$ \\
\hline
\end{tabular}

" $(P<0.05)$ significant difference in relation to the No Steatosis group in G2

$\S(P<0.05)$ significant difference in relation to the Grade I group in G2 
TABLE 5. Frequencies of variables related to hormone replacement therapy according to NAFLD diagnosis

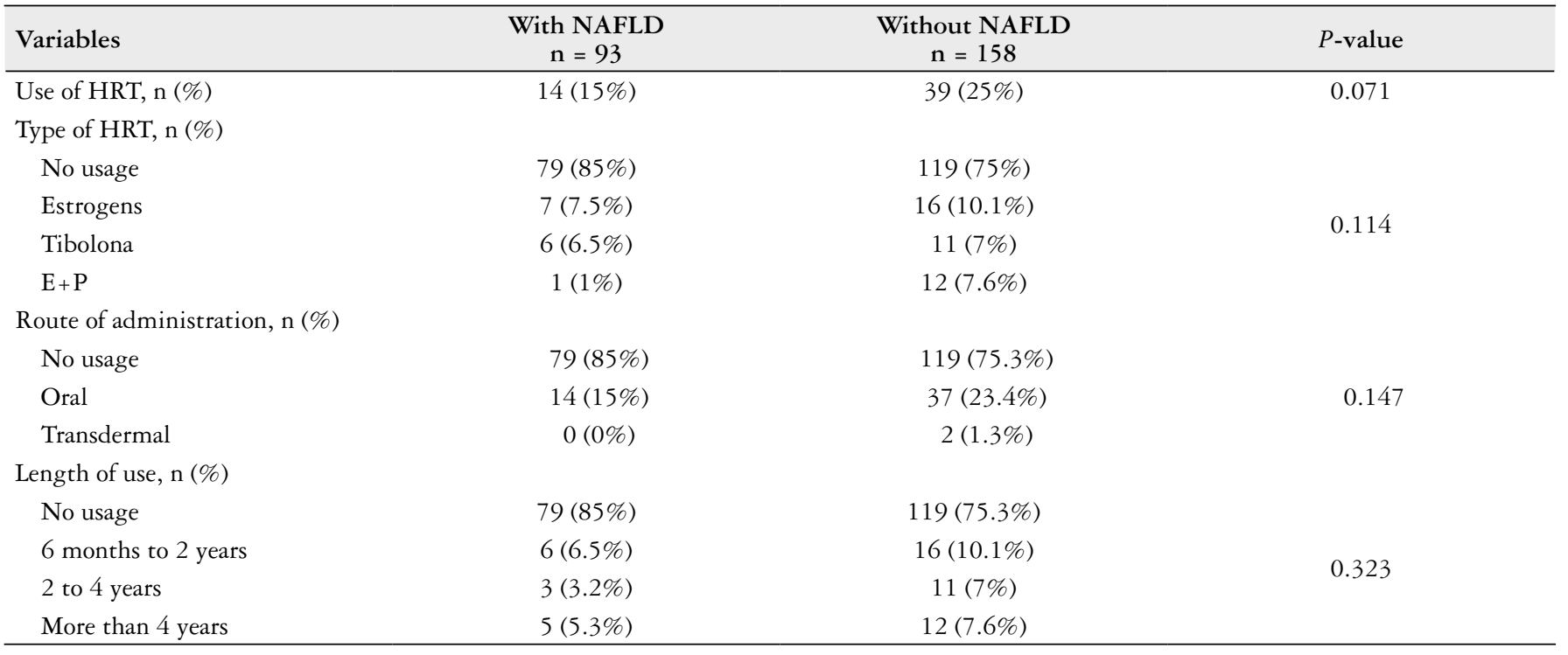

NAFLD: Non-alcoholic fatty liver disease; HRT: hormone replacement therapy; E+P: estrogens and progesterone usage

TABLE 6. Multivariate analyses of associated factors to NAFLD development among postmenopausal women

\begin{tabular}{lcccc}
\hline \multirow{2}{*}{ Risk factor } & \multirow{2}{*}{$\begin{array}{l}\text { Odds } \\
\text { Ratio }\end{array}$} & \multicolumn{2}{c}{$95 \%$ CI } & \\
\cline { 3 - 4 } & & LL & UL & \\
\hline Obesity & 1.91 & 1.01 & 3.61 & 0.046 \\
Metabolic syndrome & 2.02 & 1.11 & 3.69 & 0.022 \\
HOMA-IR $\geq 3.0$ & 3.73 & 1.63 & 8.53 & 0.002 \\
HRT & 0.87 & 0.42 & 1.78 & 0.695 \\
\hline
\end{tabular}

CI: confidence interval; LL: lower limit; UL: upper limit; HOMA-IR: homeostatic model assessment of insulin resistance; HRT: hormone replacement therapy

\section{DISCUSSION}

There is not much information about the NAFLD and HRT in PMW. Some reports are experimental or include patients with chronic hepatitis $\mathrm{C}(\mathrm{CHC})$ and type 2 diabetes.

Although the present sample of PMW has revealed a higher frequency of NAFLD, it was lower among those who referred HRT use, similar to the findings described in another study ${ }^{(11)}$.

Despite some researchers find no differences between the effects of HRT on hepatic proteins sensitive to estrogen regarding different routes of administration ${ }^{(20)}$, there are reports that the oral route leads the liver tissue to a supra physiological concentration of these hormones by hepatic first-pass effect ${ }^{(18)}$, altering the lipid metabolism by decreasing hepatic lipase activity, which would not happen in transdermal route ${ }^{(23)}$.

NAFLD was also studied in premenopausal, postmenopausal and polycystic ovary syndrome women by Gutierrez-Grobe et al. ${ }^{(10)}$ who observed higher index in polycystic ovary syndrome and postmenopausal than those premenopausal ones. The authors suggested that estrogens might have a protective effect against NAFLD in women and this drug protection against liver injury have also been suggested for others studies. One of them showed that physiological concentration of estrogen inhibits spontaneous secretion of pro-inflammatory cytokines such as interleukins (IL) -1, IL-6 and tumor necrosis factor alpha. However, after menopause and the decreased of ovarian hormone production these cytokines levels could increase ${ }^{(8)}$. Villa et al. ${ }^{(22)}$ observed that the estrogens-deprived environment in PMW with chronic hepatitis $\mathrm{C}$ virus $(\mathrm{CHC})$ had influence in progression to fibrosis. There are reports that estrogen inhibits the myofibroblastic transformation of rat stellate cells that are responsible for hyper secretion of collagen and fibrosis, pointing to a possible anti fibrotic effect of this drug ${ }^{(26)}$.

A hepatic anti fibrogenic effect of HRT has also been referred in menopausal patients using HRT with the diagnosis of chronic hepatitis $\mathrm{C}^{(4)}$, and there are evidences of less hepatic injury during pregnancy in women with chronic hepatitis $\mathrm{C}^{(9)}$, pointing to an antifibrogenic effect of endogenous estrogen. The relevance of HRT in patients with $\mathrm{CHC}$ was also evaluated by Codes et al..$^{(4)}$ who observed that steatosis was more common and severe in menopausal women. Moreover the presence of liver fibrosis was lower among the women who referred HRT use ${ }^{(4)}$. Shimizu and Ito $^{(19)}$ also evaluated patients with $\mathrm{CHC}$ and observed a beneficial effect of estradiol on the progression of chronic liver disease.

The study showed that the frequency of MS was lower in the HRT group when compared with the group without HRT. One possible hypothesis for these results could be the contribution of the HRT to the reduction of abdominal visceral fat. The group without NAFLD on HRT also had a higher proportion of women with a normal body mass index. These findings may suggest that HRT could promote weight reduction. 
Menopause has been associated with higher risk of MS development, even after adjustment for confounders such as age, body mass index, family income, and lack of physical activity ${ }^{(17)}$. In this sample of menopausal women, NAFLD was associated with well-known risk factors such as: obesity, MS and IR in the multivariate analysis.

Hamaguchi et al. ${ }^{(11)}$ suggested that aging is a risk factor for NAFLD in premenopausal women, independent of weight gain or influence of MS. In addition, results from the authors showed higher frequency of NAFLD in PMW who did not use HRT when compared to premenopausal and postmenopausal women who referred HRT usage. The logistic model did not suggest that HRT could be a risk factor for NAFLD development.

Results of this investigation are in concordance with these data ${ }^{(11)}$ and also suggested that HRT it is not related to NAFLD development. The NAFLD prevalence is higher in women not on HRT.

The HRT use was higher in younger PMW (up to 50 years old) and was lower in single women. It is possible, that these women are being influenced by their partners to use this therapy to reduce distressing symptoms and improve sexual enjoyment ${ }^{25)}$. These women may also be encouraged by their gynecologists, who aim to reduce the risk of diseases resulting from estrogens deprivation, such as osteoporosis fractures, type 2 diabetes, cardiovascular disease, and colorectal cancer ${ }^{(2)}$. Low rates of insulin resistance were observed in women using HRT, regardless of the diagnosis of NAFLD, and these findings may confirm the possible beneficial effect of this therapy describes before.

Significant alterations of ferritin e ALT levels in PMW with steatosis grades II e III on abdominal ultrasound were observed in women that not use HRT. These results may suggest a possible relation of HRT in a less liver injury, and they are in agreement with a study performed in Scotland, which suggested that HRT improved the results of liver-enzyme levels in women with type 2 diabetes ${ }^{(16)}$. However, in both studies was not performed liver biopsy, that remains the gold standard for diagnosis and staging of hepatic fibrosis ${ }^{(24)}$.

In conclusion, this study showed elevated frequency of NAFLD in PMW; metabolic syndrome and insulin resistance index were significantly elevated in PMW who have not used HRT. These results suggest that HRT may have a potential benefit effect on NAFLD, and strongly emphasis the relevance to investigate the causal relationship between HRT and NAFLD throughout a prospective cohort with liver biopsy.

\section{ACKNOWLEDGMENTS}

We want to thank Cláudia Gadelha, Debora Leite, Gerson Bragagnoli, Manoel Florentino de Medeiros Neto and Paulo Schwingel for their collaboration during this investigation.

Florentino GSA, Cotrim HP, Vilar CP, Florentino AVA, Guimarães GMA, Barreto VST. Doença hepática gordurosa não alcoólica em mulheres menopausadas. Arq Gastroenterol. 2013,50(3):180-5.

RESUMO - Contexto - A doença hepática gordurosa não alcoólica (DHGNA) é comum em mulheres na pós-menopausa. Esta condição está associada à síndrome metabólica. No entanto, a influência da terapia de reposição hormonal no desenvolvimento da DHGNA nessas mulheres necessita ser investigada. Este estudo teve como objetivo descrever as características clínicas da DHGNA em mulheres na pós-menopausa e, a relação entre terapia de reposição hormonal e esta doença. Métodos - De abril de 2009 a abril de 2011, 292 mulheres pós-menopausadas do Sistema Único de Saúde foram selecionados, e 251 foram incluídas neste estudo. A menopausa foi definida como a ausência de menstruação durante 12 meses consecutivos em mulheres saudáveis. Os critérios para diagnostico da DHGNA foram: presença de esteatose na ultra-som abdominal, história de consumo de álcool menor que $20 \mathrm{~g} /$ dia e exclusão de outras doenças hepáticas. Todas as mulheres foram submetidas a uma avaliação clínica. Para a obtenção dos resultados foram realizadas as análises uni e multivariada. Resultados - A média de idade foi de 56,5 \pm 6,7 anos. O uso de terapia de reposição hormonal foi referido por 21,1\% (53) das mulheres e 78,9\% (198) negaram seu uso. A prevalência de DHGNA foi de 37,1\% (93/251) nas mulheres pós-menopausadas, sendo de 26,4\% (14/53) no grupo em uso de terapia de reposição hormonal e 39,9\% (79/198) no grupo sem uso desta terapia. A gama-glutamil transpeptidase $(P=0,001)$, alanina transaminase $(P<0,01)$, ferritina $(P<0,001)$ e resistência à insulina (obtida pelo modelo de avaliação homeostática de resistência à insulina $\geq 3)(P<0,001)$ foram maiores nas mulheres com DHGNA que não referiram o uso da terapia de reposição hormonal. A síndrome metabólica também foi mais frequente em mulheres com DHGNA, que não utilizaram a terapia de reposição hormonal. Conclusão - Estes dados sugerem uma elevada prevalência de DHGNA em mulheres na pós-menopausa, e ainda apontam para uma associação negativa da terapia de reposição hormonal com a DHGNA.

DESCRITORES - Fígado gorduroso. Terapia de reposição hormonal. 


\section{REFERENCES}

1. Arkin H, Colton R. Tables for statisticians. New York: Barnes \& Noble, 1959.

2. Canderelli R, Leccesse LA, Miller NL, Unruh Davidson J. Benefits of hormone replacement therapy in postmenopausal women. J Am Acad Nurse Pract. 2007;19:635-41.

3. Clark JM. The epidemiology of nonalcoholic fatty liver disease in adults. J Clin Gastroenterol .2006;40:S5-10.

4. Codes L, Asselah T, Cazals-Hatem D, Tubach F, Vidaud D, Paraná R, Bedossa $\mathrm{P}$, Bedossa P, Valla D, Marcellin P. Liver fibrosis in women with chronic hepatitis $\mathrm{C}$ : evidence for the negative role of the menopause and steatosis and the potential benefit of hormone replacement therapy. Gut 2007;56:390-5.

5. Coral G, de Mattos AA, de Mattos AZ, dos Santos DE. [Steatosis and non-alcoholic steatohepatitis in patients with chronic hepatitis due to hepatitis $\mathrm{C}$ virus infection]. Arq Gastroenterol. 2006;43:265-8.

6. Corriveau P, Paquette A, Brochu M, Prud'homme D, Rabasa-Lhoret R, Lavoie JM. Resistance training prevents liver fat accumulation in ovariectomized rats. Maturitas 2008;59:259-67.

7. de Moura Almeida A, Cotrim HP, Barbosa DB, de Athayde LG, Santos AS, Bitencourt AG, de Freitas LA, Rios A, Alves E. Fatty liver disease in severe obese patients: diagnostic value of abdominal ultrasound. World J Gastroenterol. 2008; $14: 1415-8$.

8. Di Martino V, Lebray P, Myers RP, Pannier E, Paradis V, Charlotte F, Moussalli J, Thabut D, Buffet C, Poynard T. Progression of liver fibrosis in women infected with hepatitis C: long-term benefit of estrogens exposure. Hepatology 2004:40:1426-33.

9. Gervais A, Bacq Y, Bernuau J, Martinot M, Auperin A, Boyer N, Kilani A, Erlinger S, Valla D, Marcellin P. Decrease in serum ALT and increase in serum HCV RNA during pregnancy in women with chronic hepatitis C. J Hepatol. 2000;32:293-9.

10. Gutierrez-Grobe Y, Ponciano-Rodríguez G, Ramos MH, Uribe M, Méndez-Sánchez N. Prevalence of non alcoholic fatty liver disease in premenopausal, posmenopausal and polycystic ovary syndrome women: the role of estrogens. Ann Hepatol. 2010;9:402-9

11. Hamaguchi M, Kojima T, Ohbora A, Takeda N, Fukui M, Kato T. Aging is a risk factor of nonalcoholic fatty liver disease in premenopausal women. World $\mathrm{J}$ Gastroenterol. 2012;18:237-43.

12. Karnikowski M, Córdova C, Oliveira RJ, Karnikowski MG, Nóbrega O deT. Non-alcoholic fatty liver disease and metabolic syndrome in Brazilian middle-aged and older adults. Sao Paulo Med J. 2007;125:333-7.

13. Lavoie JM, Pighon A. NAFLD, estrogens, and physical exercise: the Animal Model. J Nutr Metab. 2012;2012:914938.

14. Marfell-Jones M. International standards for anthropometric assessment. Rev. ed. Potchefstroom, South Africa: International Society for the Advancement of Kinanthropometry. 2006.

15. Matthews DR, Hosker JP, Rudenski AS, Naylor BA, Treacher DF, Turner RC. Homeostasis model assessment: insulin resistance and beta-cell function from fasting plasma glucose and insulin concentrations in man. Diabetologia $1985 ; 28: 412-9$

16. McKenzie J, Fisher BM, Jaap AJ, Stanley A, Paterson K, Sattar N. Effects of HRT on liver enzyme levels in women with type 2 diabetes: a randomized placebo-controlled trial. Clin Endocrinol. 2006;65:40-4.

17. Park YW, Zhu S, Palaniappan L, Heshka S, Carnethon MR, Heymsfield SB. The metabolic syndrome: prevalence and associated risk factor findings in the US population from the Third National Health and Nutrition Examination Survey, 1988-1994. Arch Intern Med. 2003;163:427-36.

18. Rosa-e-Silva AC, Melo AS. A importância da via de administração na terapia hormonal do climatério. Femina 2010;38:279-85.

19. Shimizu I, Ito S. Protection of estrogens against the progression of chronic liver disease. Hepatol Res. 2007;37:239-47.

20. Sitruk-Ware R, Plu-Bureau G, Menard J, Conard J, Kumar S, Thalabard JC, Tokay B, Bouchard P. Effects of oral and transvaginal ethinyl estradiol on hemostatic factors and hepatic proteins in a randomized, crossover study. J Clin Endocrinol Metab. 2007;92:2074-9.

21. Suzuki A, Abdelmalek MF. Nonalcoholic fatty liver disease in women. Womens Health 2009;5:191-203

22. Villa E, Karampatou A, Cammà C, Di Leo A, Luongo M, Ferrari A, Petta S, Losi L, Taliani G, Trande P, Lei B, Graziosi A, Bernabucci V, Critelli R, Pazienza P, Rendina M, Antonelli A, Francavilla A. Early menopause is associated with lack of response to antiviral therapy in women with chronic hepatitis C. Gastroenterology 2011;140:818-29.

23. Walsh BW, Li H, Sacks FM. Effects of postmenopausal hormone replacement with oral and transdermal estrogen on high density lipoprotein metabolism. J Lipid Res. 1994;35:2083-93

24. Wieckowska A, Feldstein AE. Diagnosis of nonalcoholic fatty liver disease: invasive versus noninvasive. Semin Liver Dis. 2008;28:386-95.

25. Wren BG. The benefits of oestrogen following menopause: why hormone replacement therapy should be offered to postmenopausal women. Med J Aust. 2009;190:321-5.

26. Yasuda M, Shimizu I, Shiba M, Ito S. Suppressive effects of estradiol on dimethylnitrosamine-induced fibrosis of the liver in rats. Hepatology 1999;29:719-27.

27. Yatsuji S, Hashimoto E, Tobari M, Tokushige K, Shiratori K. Influence of age and gender in Japanese patients with non-alcoholic steatohepatitis. Hepatol Res. 2007;37:1034-43. 